Article

\title{
Numerical Modelling of Thermal Insulation of Reinforced Concrete Ceilings with Complex Cross-Sections
}

\author{
Łukasz Drobiec ${ }^{1, *(\mathbb{D})}$, Rafał Wyczółkowski ${ }^{2}$ and Artur Kisiołek ${ }^{3}$ (I) \\ 1 Department of Building Structures, Silesian University of Technology, ul. Akademicka 5, \\ 44-100 Gliwice, Poland \\ 2 Department of Production Management, Czestochowa University of Technology, Armii Krajowej 19, \\ 42-200 Częstochowa, Poland; rwyczolkowski@wip.pcz.pl \\ 3 Institute of Economics, The Great Poland University of Social and Economics in Środa Wlkp., Surzyńskich 2, \\ 63-000 Środa Wlkp, Poland; a.kisiolek@wwsse.pl \\ * Correspondence: lukasz.drobiec@polsl.pl
}

Received: 23 March 2020; Accepted: 8 April 2020; Published: 11 April 2020

check for updates

Featured Application: The paper shows how big differences are obtained between the standard approach to calculating the heat transfer coefficient of ceilings with complex geometries and accurate numerical calculations.

\begin{abstract}
The article describes the results of numerical analyses and traditional calculations of the heat transfer coefficient in ceilings with a complex cross-section, and with materials of varying density built-in inside the cross-section. Prefabricated prestressed reinforced concrete, composite reinforced, and ribbed reinforced concrete ceilings were analyzed. Traditional calculations were carried out in accordance with the EN ISO 6946:2017 standard, while the numerical analyses were carried out in a program based on the finite element method (FEM). It has been shown that calculations can be a good alternative to nondestructive testing (NDT) and laboratory tests, whose use in the case of ceilings with different geometries is limited. The differences between the calculations carried out in accordance with EN ISO 6946:2017, and the results of numerical analyses are $12 \%-39 \%$. The way the air voids are taken into account has an impact on the calculation results. In the traditional method, an equivalent thermal conductivity coefficient was used, while in the numerical analysis, the coefficient was selected from the program's material database. Since traditional calculations require simplifications, numerical methods should be considered to give more accurate results.
\end{abstract}

Keywords: numerical modelling; reinforced concrete ceilings; thermal insulation; heat transfer coefficient

\section{Introduction}

The erection of a building with reinforced concrete ceilings in accordance with the principles of sustainable development requires an accurate determination of the thermal insulation of the ceiling [1-3]. At a certain ceiling thickness, thermal insulation can be improved in two ways. The first way is to use materials with a low thermal conductivity coefficient in the partition. The second way is related to the construction of the partition. The use of insulation materials inside the ceiling, in places where there are free spaces, significantly reduces the intensity of heat flow. However, constructions with complex geometries are then created.

The heat transfer coefficient can be determined by conducting tests (nondestructive, laboratory) or by making calculations. Nondestructive testing methods are currently developing very 
dynamically [4-7] based on advanced mathematical models, including artificial intelligence [8,9] and machine learning [10-12]. However, conducting such tests usually requires the use of specialized equipment [13,14]. In the case of thermal insulation tests, nondestructive methods offer the possibility of testing homogeneous materials in small areas $[15,16]$. In practice, therefore, laboratory tests are performed more often. As in the case of nondestructive testing, they will allow testing of thermal insulation of only small elements [17-20]. For ceilings with complex geometries, both nondestructive testing in small areas and laboratory testing of small samples do not give good results [21-23]. Correct results are obtained only when conducting thermal insulation tests on a natural scale, which, however, requires the construction of a full-size model, with walls, ceilings and window and door woodwork [21,22]. A good alternative here is to perform calculations using simple or complex calculation methods $[21,23,24]$. Recently, programs based on the finite element method (FEM) have been used more and more often to determine the penetration coefficient [25-27].

The article compares the values of heat transfer coefficients of ceilings obtained from calculations carried out in accordance with EN ISO 6946:2017 [28] and numerical models. Prefabricated prestressed reinforced concrete, composite reinforced concrete, and ribbed reinforced concrete ceilings with different types of fillings between reinforced concrete beams were analyzed. The analyzed ceilings have complex cross-sections.

\section{Analyzed Ceilings}

The following ceiling systems were analyzed: a prefabricated prestressed Smart channel ceiling and Teriva Panel, Teriva Base, Teriva Plus and Teriva Termo ribbed ceilings. The Smart ceiling is a $60 \mathrm{~cm}$ wide prestressed concrete slab with five $60 \times 90 \mathrm{~mm}$ air ducts, and reinforcement in the form of six $\varnothing 9.3 \mathrm{~mm}$ rods in the bottom part and two ø $6.85 \mathrm{~mm}$ rods in the top part. The section of the Smart ceiling is shown in Figure 1. The lateral edges of the prefabricated element are shaped so that after filling them with concrete, a permanent connection will occur, which will ensure proper cooperation between the panels when transferring loads. The most important parameters of the ceiling in question are summarized in Table 1.

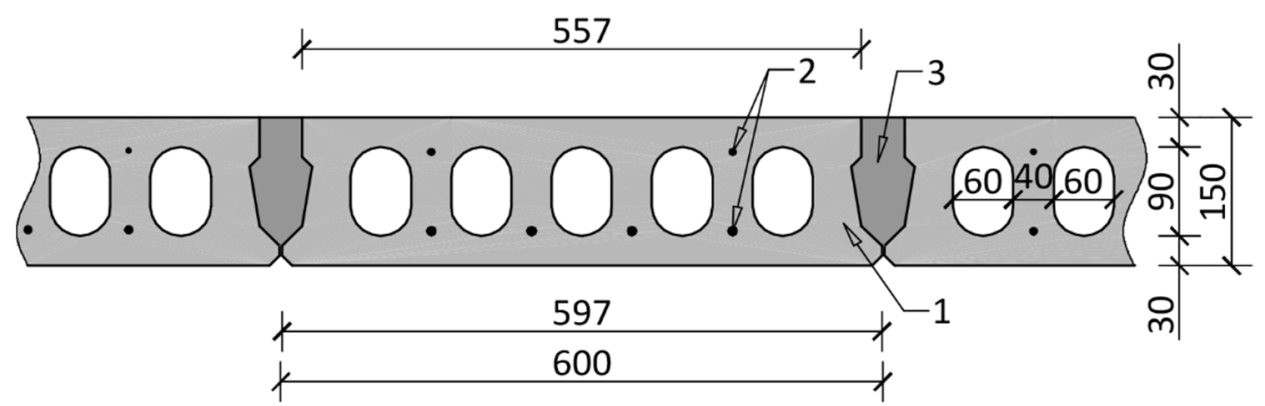

Figure 1. Cross-section of the prefabricated prestressed Smart ceiling. 1-prefabricated prestressed slab, 2-stressing cables, 3-concrete laid on site.

Table 1. Basic parameters of the Smart ceiling.

\begin{tabular}{cc}
\hline Parameter & Value \\
\hline height & $150 \mathrm{~mm}$ \\
width & $600 \mathrm{~mm}$ \\
transferred loads depending on the span & from 5.0 to $40.0 \mathrm{kN} / \mathrm{m}^{2}$ \\
prefabricated concrete class & $\mathrm{C} 40 / 50$ \\
span up to & $8.1 \mathrm{~m}$ \\
fire resistance & $\mathrm{REI} 60$ \\
weight & $250 \mathrm{~kg} / \mathrm{m}^{2}$ \\
\hline
\end{tabular}


The Teriva Panel ceiling is a prestressed composite structure with reinforced concrete laid at the construction site. The prefabricated prestressed part consists of a bottom plate $590 \mathrm{~mm}$ wide and two ribs. The space between the ribs is filled with foam concrete with a density of $400 \mathrm{~kg} / \mathrm{m}^{3}$, and a $4 \mathrm{~cm}$ layer of composite concrete is poured into the whole structure at the construction site. The cross-section through the Teriva Panel ceiling is shown in Figure 2, and its basic parameters are given in Table 2.

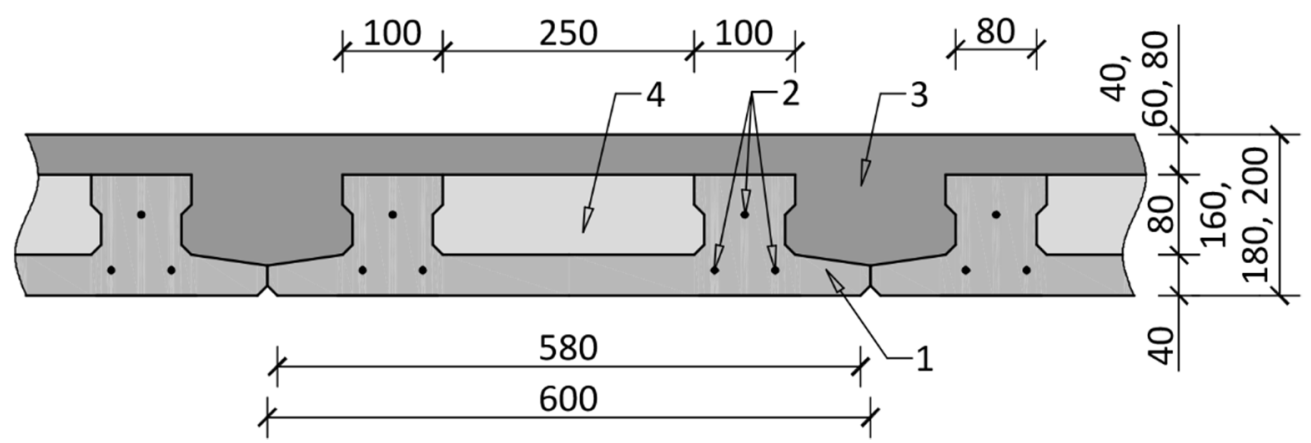

Figure 2. Cross-section of the partially prefabricated prestressed composite Teriva Panel ceiling. 1-prefabricated prestressed slab, 2-stressing cables, 3-concrete laid on site, 4-foam concrete.

Table 2. Basic parameters of the Teriva Panel ceiling.

\begin{tabular}{cc}
\hline Parameter & Value \\
\hline height & $160,180,200 \mathrm{~mm}$ \\
width & $600 \mathrm{~mm}$ \\
transferred loads depending on the span & from 2.0 to $34.4 \mathrm{kN} / \mathrm{m}^{2}$ \\
prefabricated concrete class & C $40 / 50$ \\
span up to & $7.4 \mathrm{~m}$ \\
fire resistance & $\mathrm{REI} 30$ \\
weight & $188 \mathrm{~kg} / \mathrm{m}^{2}$ \\
\hline
\end{tabular}

The Teriva Base ceiling system consists of prefabricated truss beams with a concrete foot, three-chamber filling expanded clay, and concrete hollow bricks and concrete overlay laid at the construction site. The cross-section of this ceiling is shown in Figure 3, and the basic parameters are given in Table 3.

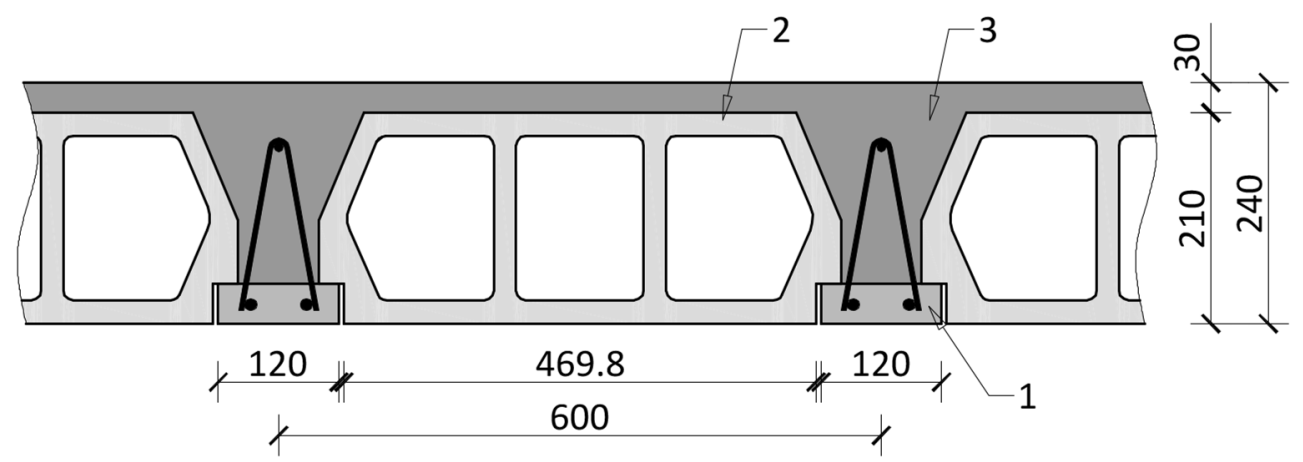

Figure 3. Cross-section of the Teriva Base thick-ribbed ceiling. 1-prefabricated truss beam, 2-filling expanded clay and concrete hollow brick, 3-concrete laid at the construction site. 
Table 3. Basic parameters of the Teriva Base ceiling.

\begin{tabular}{cc}
\hline Parameter & Value \\
\hline height & $240 \mathrm{~mm}$ \\
rib span & $600 \mathrm{~mm}$ \\
transferred load depending on the span & from $4.0 \mathrm{KN} / \mathrm{m}^{2}$ \\
prefabricated concrete class & $\mathrm{C} 20 / 25$ \\
span up to & $7.2 \mathrm{~m}$ \\
fire resistance & REI 30 \\
weight & $238 \mathrm{~kg} / \mathrm{m}^{2}$ \\
\hline
\end{tabular}

The Teriva Plus system is similar to the Teriva Base ceiling, but their difference lies in the type of filling. In the Teriva Plus case, the filling is expanded clay and concrete five-chamber hollow bricks in the so-called upper shelf as shown in Figure 4, which remains uncovered after pouring concrete into the ceiling. Thanks to this solution, the height of the complete ceiling is equal to the height of the hollow brick itself. The basic parameters of the Teriva Plus ceiling are summarized in Table 4 .

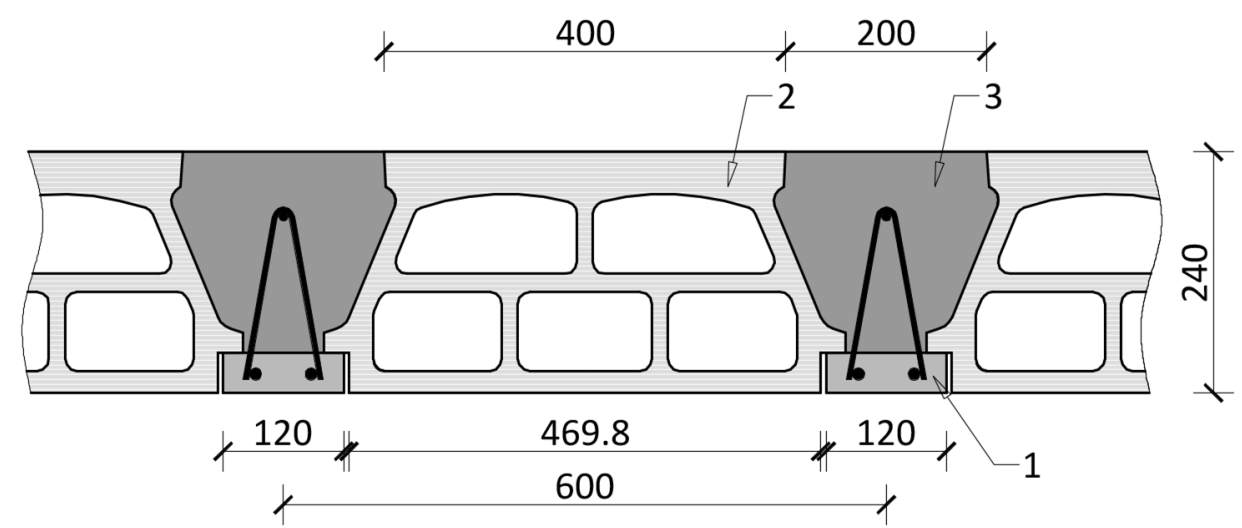

Figure 4. Cross-section of the Teriva Plus thick-ribbed ceiling. 1-prefabricated truss beam, 2-filling expanded clay and concrete hollow brick, 3 -concrete laid at the construction site.

Table 4. Basic parameters of the Teriva Plus ceiling.

\begin{tabular}{cc}
\hline Parameter & Value \\
\hline height & $240 \mathrm{~mm}$ \\
rib span & $600 \mathrm{~mm}$ \\
transferred loads depending on the span & from $4.0 \mathrm{kN} / \mathrm{m}^{2}$ \\
prefabricated concrete class & $\mathrm{C} 20 / 25$ \\
span up to & $7.2 \mathrm{~m}$ \\
fire resistance & REI 30 \\
weight & $257 \mathrm{~kg} / \mathrm{m}^{2}$ \\
\hline
\end{tabular}

The Teriva Termo ceiling is characterized by the use of expanded clay and concrete 10-chamber hollow bricks with shifted vertical walls, as shown in Figure 5. This solution eliminates the occurrence of direct thermal bridges between the upper and lower surfaces of the hollow brick, which in turn should improve the thermal properties of the ceiling. The basic parameters of the Teriva Termo ceiling are summarized in Table 5. 


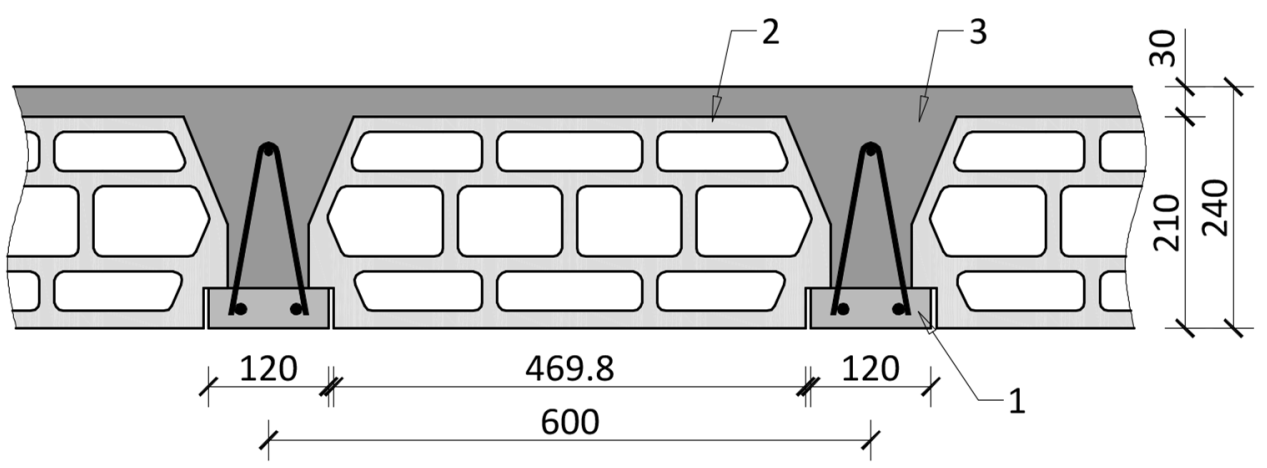

Figure 5. Cross-section of the Teriva Termo thick-ribbed ceiling. 1-prefabricated truss beam, 2-filling expanded clay and concrete hollow brick, 3-concrete laid at the construction site.

Table 5. Basic parameters of the Teriva Termo ceiling.

\begin{tabular}{cc}
\hline Parameter & Value \\
\hline height & $240 \mathrm{~mm}$ \\
rib span & $600 \mathrm{~mm}$ \\
transferred loads depending on the span & from $4.0 \mathrm{kN} / \mathrm{m}^{2}$ \\
prefabricated concrete class & $\mathrm{C} 20 / 25$ \\
span up to & $7.2 \mathrm{~m}$ \\
fire resistance & REI 30 \\
weight & $228 \mathrm{~kg} / \mathrm{m}^{2}$ \\
\hline
\end{tabular}

\section{Traditional Calculations}

The thermal insulation of the discussed ceiling systems was described by means of three parameters: thermal resistance, heat transfer coefficient, and heat transfer resistance. $R_{T}$ thermal resistance is defined as the quotient of the temperature difference and the heat flux density in a steady state, which in the case of a flat homogeneous layer, equals the quotient of the thickness and the thermal conductivity coefficient. The heat transfer coefficient $U$ for a flat partition is defined as the heat flux in a steady state divided by the surface area and by the difference in ambient (fluids) temperatures on both sides of the partition. The heat transfer resistance $R_{U}$ of a flat partition is the sum of its thermal resistance and heat transfer resistance. At the same time, this parameter is the inverse of the heat transfer coefficient.

First, the thermal conductivity resistance was determined. This parameter was calculated in accordance with the principles given in the EN ISO 6946:2017 standard [28]. Since all considered ceilings are partitions consisting of thermally heterogeneous layers, $R_{T}$ resistance was calculated from the formula:

$$
R_{T}=\frac{R_{T}^{\prime}+R_{T}^{\prime \prime}}{2}
$$

where $R_{T}^{\prime}$ - upper limit of thermal resistance: $R_{T}^{\prime \prime}$-lower limit of thermal resistance.

This approach therefore requires the division of the partition in question into sections and layers, the sections being parallel to the direction of the heat flow and the layers perpendicular. The division of the ceiling into sections concerns the determination of the upper thermal resistance limit. This is done in such a way that the separated sections consist of homogeneous layers. On this basis, the resistance is calculated as a parallel connection of the resistance of individual sections assuming one-dimensional heat flow perpendicular to the surface of the layers:

$$
\frac{1}{R_{T}^{\prime}}=\frac{f_{1}}{R_{T 1}^{\prime}}+\frac{f_{1}}{R_{T 1}^{\prime}}+\cdots+\frac{f_{n}}{R_{T n}^{\prime}},
$$


where $R_{T i}^{\prime}$-thermal resistance of individual sections (calculated as the sum of resistance of the individual layers of a given section), $f_{i}$-relative surface area of a given section (calculated as the quotient of the surface area of a given section to the surface of the entire partition).

The division of the ceiling into layers is associated with the calculation of the lower limit of thermal resistance. This resistance is calculated as a series connection of resistances of the individual layers:

$$
R_{T}^{\prime \prime}=R_{T 1}^{\prime \prime}+R_{T 2}^{\prime \prime}+\cdots+R_{T n^{\prime}}^{\prime \prime}
$$

where $R_{T i}^{\prime \prime}$-the equivalent thermal resistance of each heterogeneous layer, calculated as the parallel connection of the resistances of the elements (homogeneous sections) present in this layer. These quantities are calculated according to the formula:

$$
\frac{1}{R_{T i}^{\prime \prime}}=\frac{f_{1}}{R_{T 1 i}^{\prime}}+\frac{f_{1}}{R_{T 1 i}^{\prime}}+\cdots+\frac{f_{n}}{R_{T n i}^{\prime}}
$$

The thermal resistance of a homogeneous ceiling element, with the exception of air layers, is described as the relationship

$$
R_{T i}=\frac{d_{i}}{k_{i}}
$$

where: $d_{i}$ - the dimension of the partition element in the direction of heat flow, $k_{i}$-thermal conductivity of the material of this element.

Most of the discussed ceilings contain free spaces filled with air in their structure. The thermal resistance of these parts of the ceilings was determined by treating them as unventilated air layers. The value of this parameter depending on the heat flow direction and layer thickness is selected from the table data [22].

After determining thermal resistance, heat transfer resistance was calculated. $R_{U}$ resistance was calculated as a series connection of the ceiling thermal resistance and heat transfer resistance:

$$
R_{U}=R_{s i}+R_{T}+R_{s e}
$$

where: $R_{s i}, R_{s o}$-resistance to heat transfer on the internal and external surfaces of the ceiling. The values of these resistances, depending on the type of partition (external or internal) and the direction of the heat flow, are presented in Table 6.

Table 6. Heat transfer resistance according to EN ISO $6946[28]$ in $\mathrm{m}^{2} \mathrm{~K} / \mathrm{W}$.

\begin{tabular}{ccc}
\hline \multirow{2}{*}{ Type of Surface } & \multicolumn{2}{c}{ Heat Flow Direction } \\
\cline { 2 - 3 } & Upwards & Downwards \\
\hline internal & 0.10 & 0.17 \\
external & 0.04 & 0.04 \\
\hline
\end{tabular}

The last of the analyzed parameters, i.e., the heat transfer coefficient $U$, was calculated as the inverse of the heat transfer resistance:

$$
U=\frac{1}{R_{U}},
$$

The methodology for determining these thermal parameters is presented in detail in one of the ceilings in publication [22].

Performing the relevant calculations, two directions of heat flow (downwards and upwards) were considered for each ceiling system when treating them as internal partitions. The values of thermal conductivity coefficients $k$ adopted for individual materials occurring in the analyzed ceilings are summarized in Table 7. 
Table 7. Calculation values of conductivity coefficients adopted for individual materials occurring in the analyzed ceilings.

\begin{tabular}{cc}
\hline Material & Coefficient $k, \mathbf{W} /(\mathbf{m} \cdot \mathbf{K})$ \\
\hline concrete & 1.70 \\
concrete overlay & 1.00 \\
foam concrete & 0.14 \\
expanded clay concrete & 0.90 \\
steel reinforcement & 58 \\
\hline
\end{tabular}

In the case of the Teriva Panel system, calculations were made for three construction variants differing in the thickness of the concrete overlay layer: Teriva Panel 160 (concrete overlay layer $40 \mathrm{~mm}$ ), Teriva Panel 180 (concrete overlay layer $60 \mathrm{~mm}$ ) and Teriva Panel 200 (concrete overlay layer $80 \mathrm{~mm}$ ). The calculation results were compared in Tables 8 and 9. Table 8 presents the results obtained for individual Teriva Panel ceiling variants, while Table 9 contains the results obtained for the Smart system and three Teriva systems: Base, Plus and Termo.

Table 8. Values of thermal parameters of various Teriva Panel ceiling variants.

\begin{tabular}{ccccc}
\hline Parameter & Unit & Teriva Panel 160 & Teriva Panel 180 & Teriva Panel 200 \\
\hline resistance $R_{T}$ & $\left(\mathrm{~m}^{2} \cdot \mathrm{K}\right) / \mathrm{W}$ & 0.190 & 0.209 & 0.227 \\
resistance $R_{U}$ flow upwards & $\left(\mathrm{m}^{2} \cdot \mathrm{K}\right) / \mathrm{W}$ & 0.390 & 0.409 & 0.427 \\
resistance $R_{U}$ flow downwards & $\left(\mathrm{m}^{2} \cdot \mathrm{K}\right) / \mathrm{W}$ & 0.530 & 0.549 & 0.567 \\
coefficient $U$ flow upwards & $\mathrm{W} /\left(\mathrm{m}^{2} \cdot \mathrm{K}\right)$ & 2.564 & 2.445 & 2.342 \\
coefficient $U$ flow downwards & $\mathrm{W} /\left(\mathrm{m}^{2} \cdot \mathrm{K}\right)$ & 1.887 & 1.821 & 1.764 \\
\hline
\end{tabular}

Table 9. Values of thermal parameters of the Smart and Teriva ceilings: Base, Plus and Termo.

\begin{tabular}{cccccc}
\hline Parameter & Unit & Smart & Teriva Base & Teriva Plus & Teriva Termo \\
\hline resistance $R_{T}$ & $\left(\mathrm{~m}^{2} \cdot \mathrm{K}\right) / \mathrm{W}$ & 0.119 & 0.280 & 0.370 & 0.534 \\
resistance $R_{U}$ flow upwards & $\left(\mathrm{m}^{2} \cdot \mathrm{K}\right) / \mathrm{W}$ & 0.319 & 0.480 & 0.570 & 0.734 \\
resistance $R_{U}$ flow downwards & $\left(\mathrm{m}^{2} \cdot \mathrm{K}\right) / \mathrm{W}$ & 0.459 & 0.620 & 0.710 & 0.874 \\
coefficient $U$ flow upwards & $\mathrm{W} /\left(\mathrm{m}^{2} \cdot \mathrm{K}\right)$ & 3.205 & 2.083 & 1.754 & 1.362 \\
coefficient $U$ flow downwards & $\mathrm{W} /\left(\mathrm{m}^{2} \cdot \mathrm{K}\right)$ & 2.179 & 1.613 & 1.408 & 1.144 \\
\hline
\end{tabular}

Among the calculated parameters, the heat transfer resistance obtained for the heat flow downwards should be considered the most important from a practical point of view. The comparison of the values of this parameter shows that increasing the thickness of the concrete overlay from $40 \mathrm{~mm}$ (Teriva Panel 160) to $60 \mathrm{~mm}$ (Teriva Panel 180) and $80 \mathrm{~mm}$ (Teriva Panel 200) increases the heat transfer resistance of these systems by $3.6 \%$ and $7 \%$, respectively.

The lowest value of penetration resistance is found in the Smart ceiling, for which this parameter is $0.459\left(\mathrm{~m}^{2} \cdot \mathrm{K}\right) / \mathrm{W}$. This result is caused by two factors. First of all, this ceiling has the lowest height (only $15 \mathrm{~cm}$ ), and as it results from Equation (5), the thermal resistance of the layer is greater the larger its size. The second factor in this respect is the relatively high height of the air ducts, which contributes to the intensification of heat exchange due to convection. In turn, the best insulating properties are characterized by the Teriva Termo ceiling, for which the analyzed parameter is $0.874\left(\mathrm{~m}^{2} \cdot \mathrm{K}\right) / \mathrm{W}$. This result is due to the ceiling height, which in this case is $30 \mathrm{~cm}$, and the relatively small size of the air chambers within the hollow blocks. The latter factor significantly reduces air convection.

For a more detailed analysis of the results obtained, the percentage excess of heat transfer resistance was determined in relation to the value obtained for the Smart ceiling. This parameter was calculated according to the relationship:

$$
\delta R=\frac{R_{x}-R_{0}}{R_{0}} \cdot 100 \%
$$


where $R_{x}$-heat transfer resistance of the analyzed ceiling, $R_{0}$-heat transfer resistance of the Smart ceiling.

The results of calculations of the parameter $\delta R$ obtained for both directions of the heat flow are summarized in Table 10. As can be seen, the higher value of the surplus occurs at the upward heat flow. This result should be explained by the relatively large proportion of air convection in free spaces of the Smart panel, which reduces its insulation. In the case of the downward heat flow, the phenomenon of convection in the air chambers does not take place. In this situation, the resistance to heat transfer of this ceiling is much higher.

Table 10. Excess percentage heat transfer resistance of individual ceiling systems in relation to the Smart ceiling.

\begin{tabular}{ccc}
\hline \multirow{2}{*}{ Type of Ceiling } & Flow Upwards & Flow Downwards \\
\cline { 2 - 3 } & $\mathbf{\%}$ & $\mathbf{\%}$ \\
\hline Teriva Panel 160 & 25 & 15 \\
Teriva Panel 180 & 31 & 20 \\
Teriva Panel 200 & 37 & 24 \\
Teriva Base 3-chamber & 54 & 35 \\
Teriva Plus & 79 & 46 \\
Teriva Termo 10-chamber & 131 & 90 \\
\hline
\end{tabular}

For the downward flow of heat, the percentage surplus for individual ceilings is between $15 \%$ (Teriva Panel 160) and 90\% (Teriva Termo). This means that the Teriva Termo ceiling has almost twice the thermal insulation compared to the Smart ceiling. For the upward flow, this parameter in turn varies from $25 \%$ to $131 \%$. Larger values in this case are caused by a greater effect of convection on the thermal resistance of the Smart ceiling.

Building partitions, including ceilings, which are elements of the outer casing or elements separating rooms with different microclimatic parameters, must meet specific requirements for thermal insulation. The relevant regulation [12] is required to do so. According to this document, the values of the heat transfer coefficient of walls, ceilings and roofs cannot be higher than the $U_{\max }$ value. For residential, collective housing and public buildings, the requirements for ceilings are as follows:

- ceilings under unheated attics or over passages when the internal temperature of the rooms is higher than $16{ }^{\circ} \mathrm{C} U_{\max }=0.25 \mathrm{~W} /\left(\mathrm{m}^{2} \cdot \mathrm{K}\right)$,

- ceilings under unheated attics or over passages when the internal temperature of the rooms is less than or equal to $16^{\circ} \mathrm{C} U_{\max }=0.50 \mathrm{~W} /\left(\mathrm{m}^{2} \cdot \mathrm{K}\right)$,

- ceilings over unheated basements and closed floor spaces $U_{\max }=0.45 \mathrm{~W} /\left(\mathrm{m}^{2} \cdot \mathrm{K}\right)$.

As can be see, all analyzed ceilings without an additional insulating layer do not meet the requirements. For this reason, the thickness of the foamed polystyrene layer has to be added to obtain the $U_{\text {max }}$ coefficient values required for the first and third cases. In these calculations, $0.045 \mathrm{~W} /\left(\mathrm{m}^{2} \cdot \mathrm{K}\right)$ was adopted as the calculation value of the thermal conductivity coefficient for foamed polystyrene [11]. The obtained results are summarized in Tables 11 and 12. For Teriva Panel ceilings, the necessary foam thicknesses are approximately: $150 \mathrm{~mm}$-for $U_{\max }=0.25 \mathrm{~W} /\left(\mathrm{m}^{2} \cdot \mathrm{K}\right)$, and $75 \mathrm{~mm}$-for $U_{\max }=$ $0.45 \mathrm{~W} /\left(\mathrm{m}^{2} \cdot \mathrm{K}\right)$. For other systems, these thicknesses fall within the following ranges:

- $U_{\max }=0.25 \mathrm{~W} /\left(\mathrm{m}^{2} \cdot \mathrm{K}\right)-134.4 \div 158.3 \mathrm{~mm}$,

- $U_{\max }=0.45 \mathrm{~W} /\left(\mathrm{m}^{2} \cdot \mathrm{K}\right)-57.9 \div 81.7 \mathrm{~mm}$. 
Table 11. Thicknesses of the polystyrene layer necessary for the analyzed ceilings to obtain the required $U$ values.

\begin{tabular}{ccccc}
\hline $\boldsymbol{U}$ & Flow & Teriva Panel 160 & Teriva Panel 180 & Teriva Panel 200 \\
\hline \multirow{2}{*}{$0.25 \mathrm{~W} /\left(\mathrm{m}^{2} \cdot \mathrm{K}\right)$} & upwards & $155.2 \mathrm{~mm}$ & $154.4 \mathrm{~mm}$ & $153.6 \mathrm{~mm}$ \\
& downwards & $149.2 \mathrm{~mm}$ & $148.4 \mathrm{~mm}$ & $147.6 \mathrm{~mm}$ \\
\multirow{2}{*}{$0.45 \mathrm{~W} /\left(\mathrm{m}^{2} \cdot \mathrm{K}\right)$} & upwards & $78.7 \mathrm{~mm}$ & $77.9 \mathrm{~mm}$ & $77.1 \mathrm{~mm}$ \\
& downwards & $72.7 \mathrm{~mm}$ & $71.9 \mathrm{~mm}$ & $71.1 \mathrm{~mm}$ \\
\hline
\end{tabular}

Table 12. Thicknesses of the polystyrene layer necessary for the analyzed ceilings to obtain the required $U$ values.

\begin{tabular}{cccccc}
\hline $\boldsymbol{U}$ Coefficient & Flow & Smart & Teriva Base & Teriva Plus & Teriva Termo \\
\hline \multirow{2}{*}{$0.25 \mathrm{~W} /\left(\mathrm{m}^{2} \cdot \mathrm{K}\right)$} & upwards & 158.3 & 151.4 & 147.5 & 140.5 \\
& downwards & 152.3 & 145.3 & 141.5 & 134.4 \\
$0.45 \mathrm{~W} /\left(\mathrm{m}^{2} \cdot \mathrm{K}\right)$ & upwards & 81.7 & 74.8 & 70.9 & 63.9 \\
& downwards & 75.7 & 68.8 & 64.9 & 57.9 \\
\hline
\end{tabular}

In this context, the influence of the heat flow direction is also interesting. For all systems, regardless of the $U_{\max }$ value, the difference between the thickness of the foamed polystyrene between the upward and downward heat flows does not exceed $6 \mathrm{~mm}$. This shows that the direction of heat flow has relatively little effect on the thermal insulation values of ceilings.

\section{Numerical Analyzes}

In order to determine the heat flux $Q$, numerical calculations were made in the PSI THERM program based on the finite element method. The same assumptions were made as when calculating in accordance with the guidelines of EN ISO 6946:2017 [28]. The upward flow and the downward flow were modelled. The presence of reinforcement, air voids and materials of different densities and different heat transfer coefficients were taken into account. The heat transfer coefficient in air voids was selected based on the air void database available in the computer program. The value of the heat transfer coefficient of the void is selected depending on its thickness (in the program, the thickness is graded every $5 \mathrm{~mm}$-a range of values for voids with a thickness of $5 \mathrm{~mm}$ to $300 \mathrm{~mm}$ ), depending on the direction of heat flow (horizontally, upwards, downwards) and the type of void (nonventilated or poorly ventilated). Therefore, alternative resistance was used. Ceiling models were divided into finite elements with the dimension of the side equal to $20 \mathrm{~mm}$.

The obtained results are shown in Figures 6-12. On the basis of heat flux $Q$ of the obtained numerical models, the heat transfer coefficient $U$, thermal resistance $R_{T}$, and thermal resistance of the ceiling $R_{U}$ were calculated. The results of these calculations are summarized in Tables 13 and 14 . Table 13 presents the results obtained for individual variants of the Teriva Panel ceiling, whereas Table 14 contains the results obtained for the Smart system and three Teriva systems: Base, Plus and Termo. 


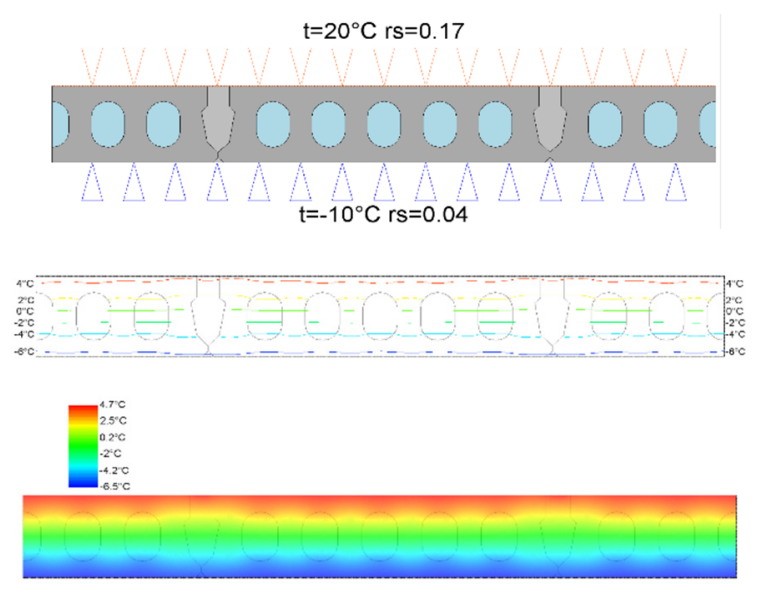

(a)
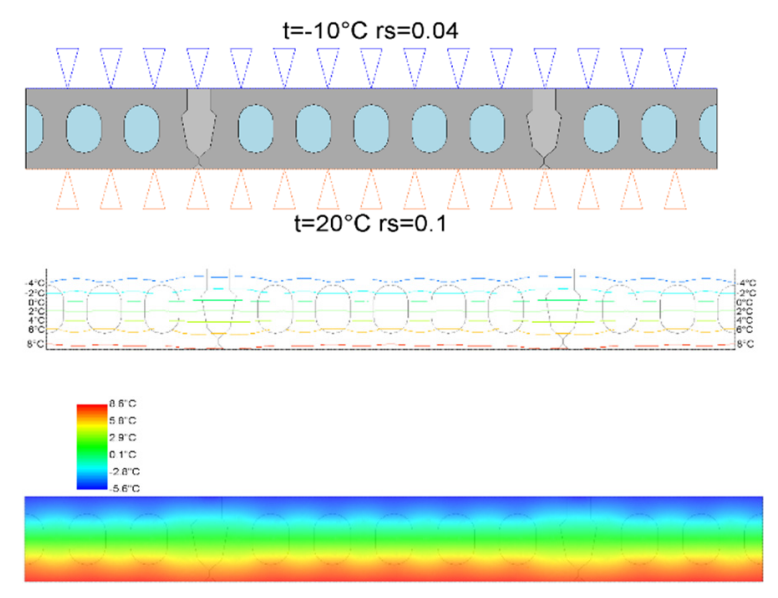

(b)

Figure 6. Results of numerical calculations of the Smart ceiling: (a) flow upwards, (b) flow downwards.

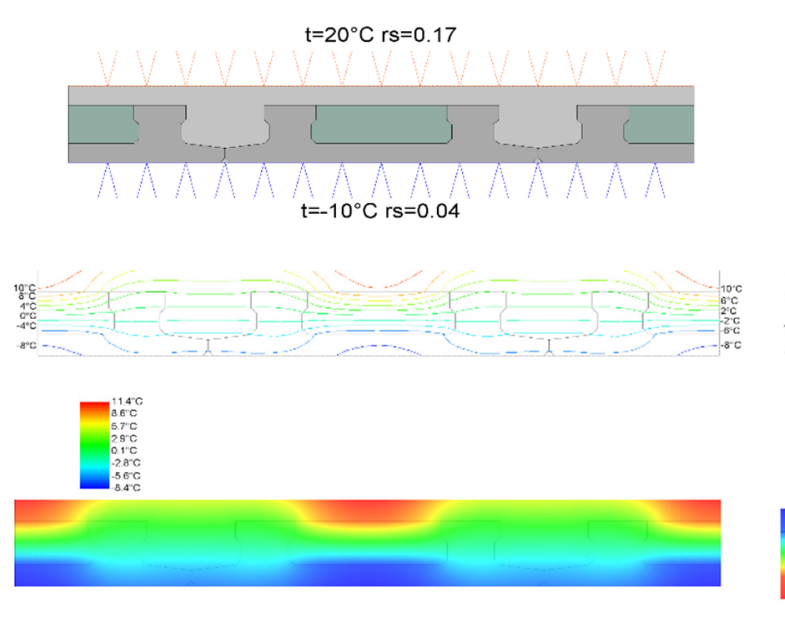

(a)
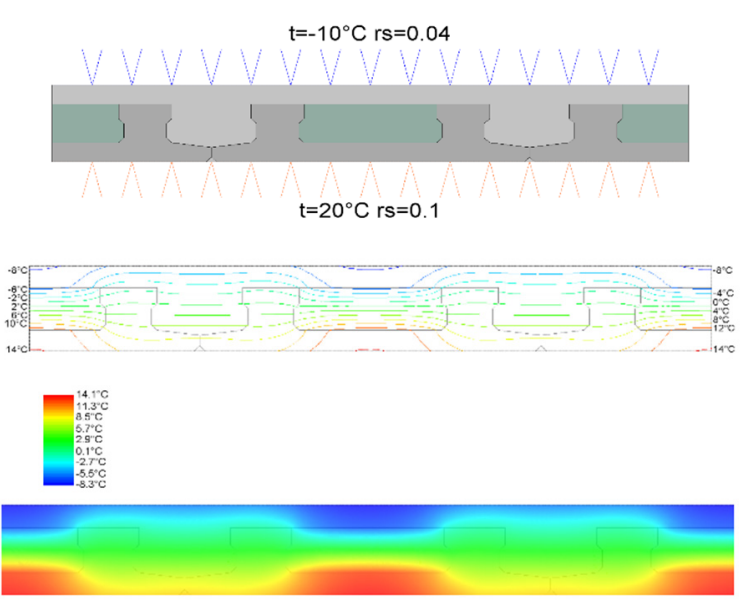

(b)

Figure 7. Results of numerical calculations of the Teriva Panel ceiling with a height of $160 \mathrm{~mm}$ : (a) flow upwards, (b) flow downwards.
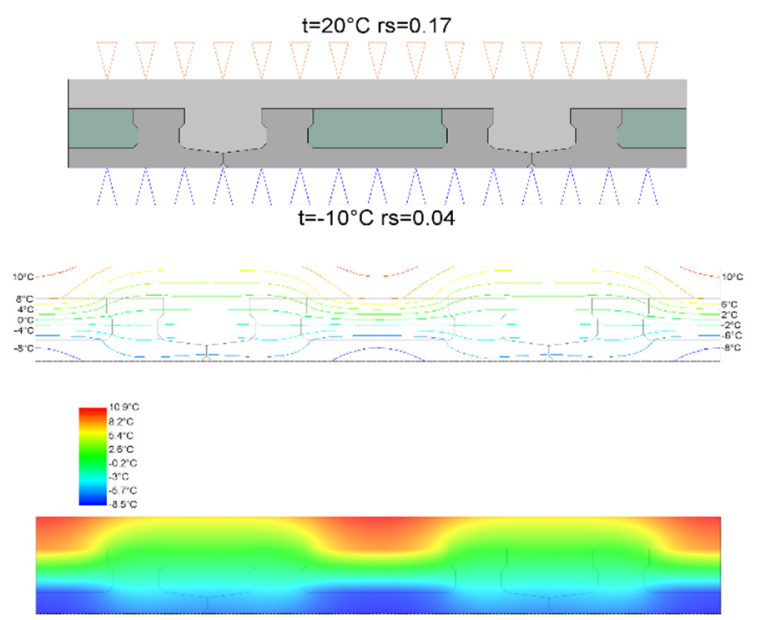

(a)
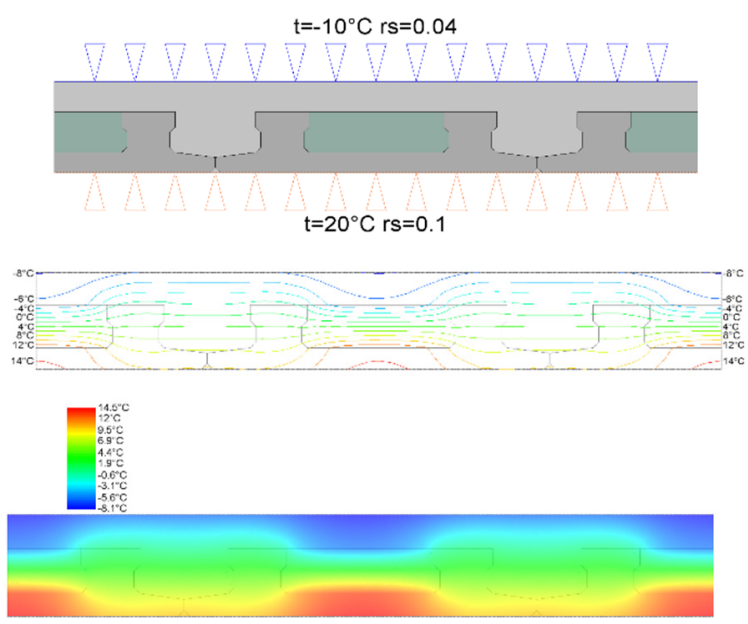

(b)

Figure 8. Results of numerical calculations of the Teriva Panel ceiling with a height of $180 \mathrm{~mm}$ : (a) flow upwards, (b) flow downwards. 

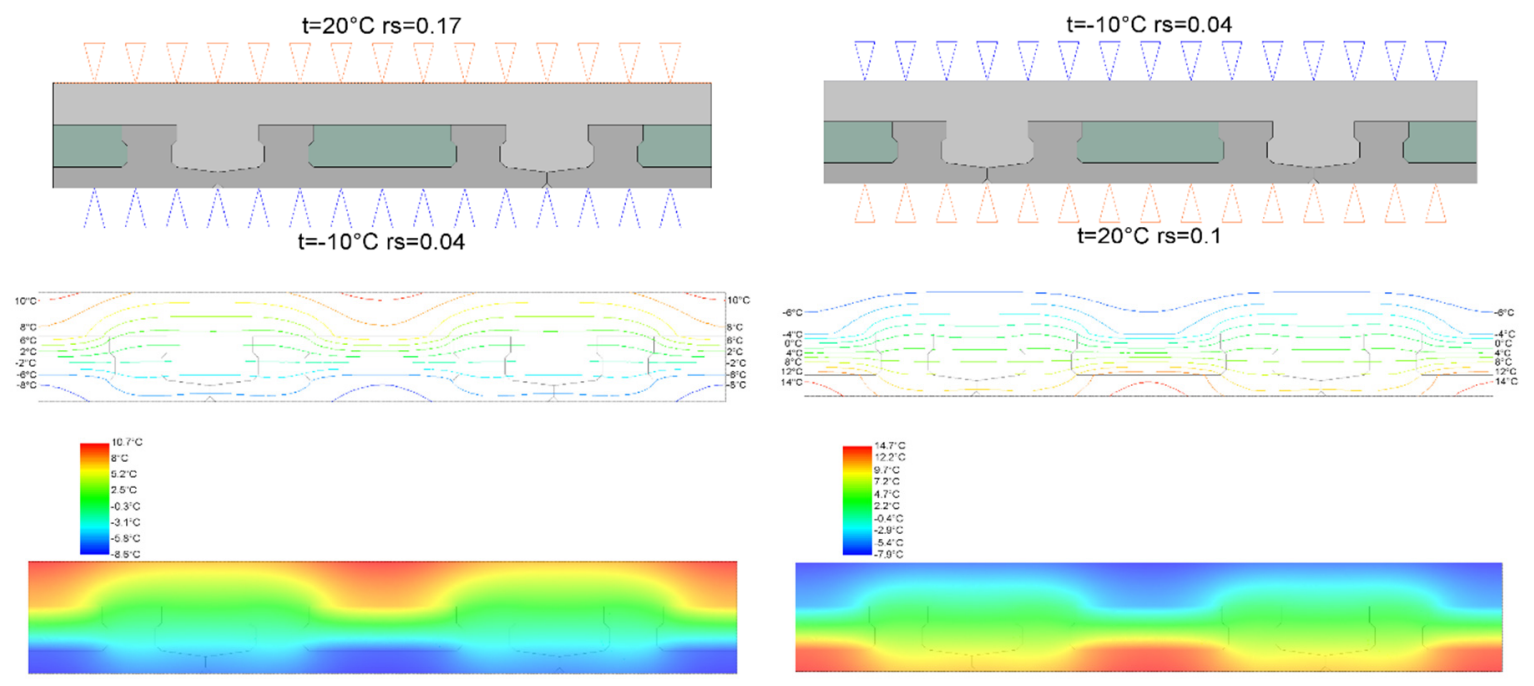

(a)

(b)

Figure 9. Results of numerical calculations of the Teriva Panel ceiling with a height of $200 \mathrm{~mm}$ : (a) flow upwards, (b) flow downwards.
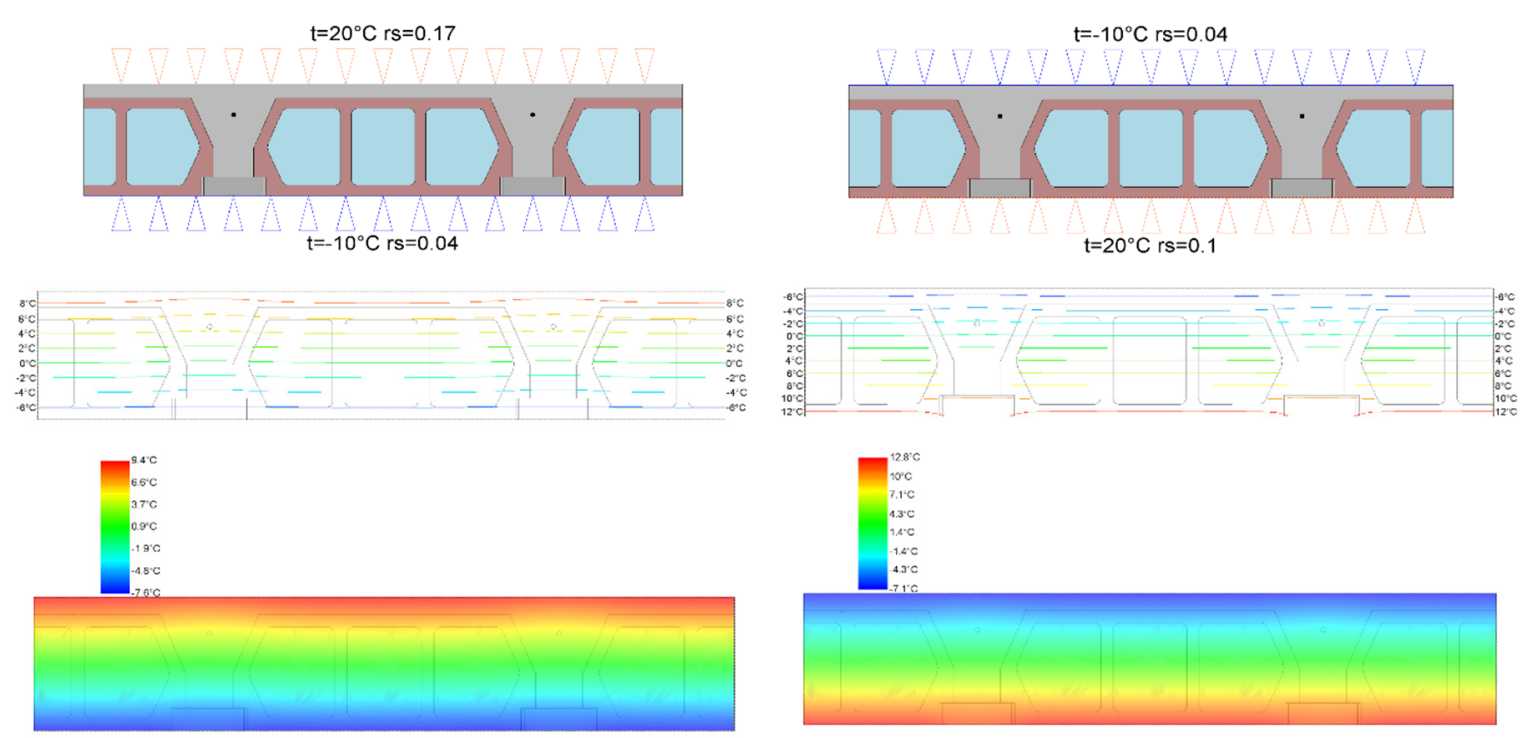

(a)

(b)

Figure 10. Results of Teriva Base ceiling calculations: (a) flow upwards, (b) flow downward. 


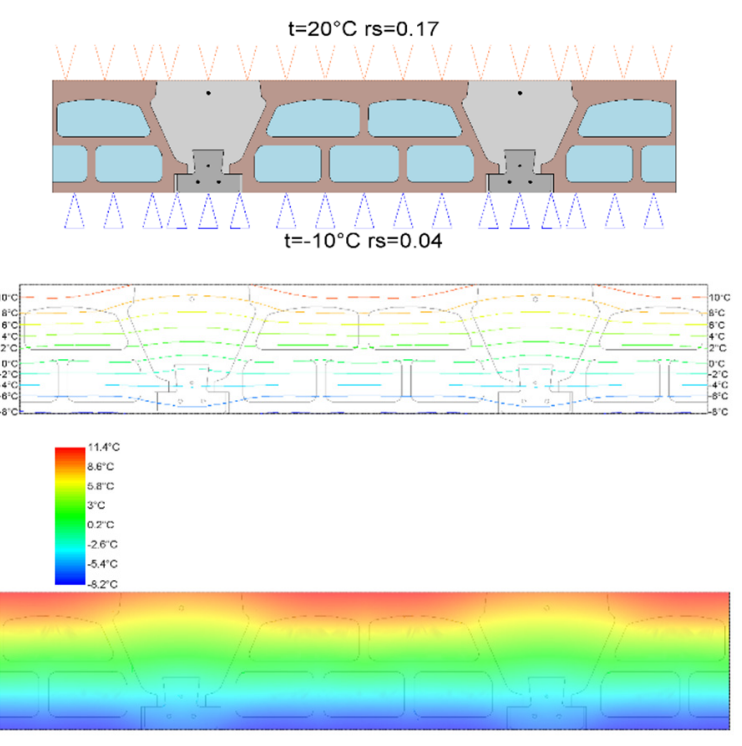

(a)
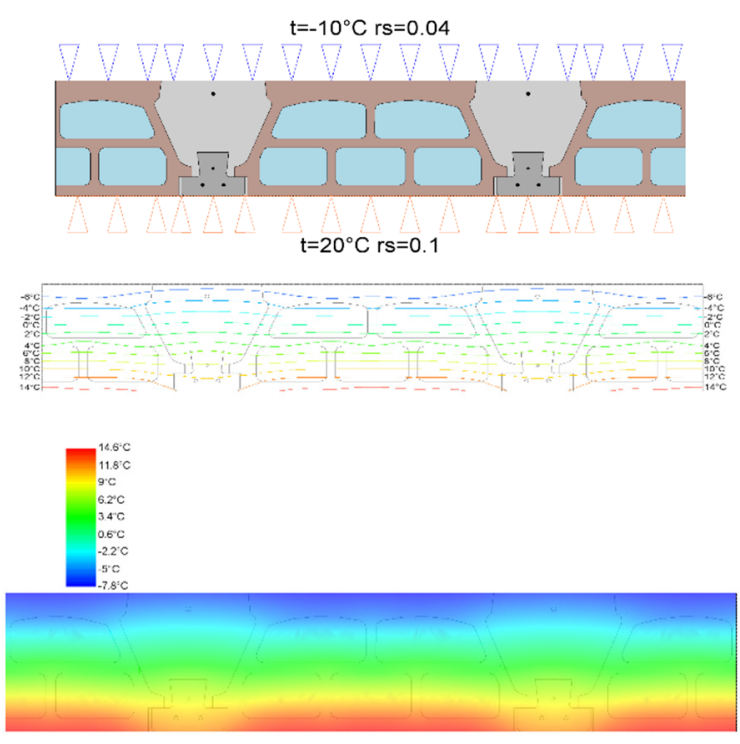

(b)

Figure 11. Results of Teriva Plus ceiling calculations: (a) flow upwards, (b) flow downwards.
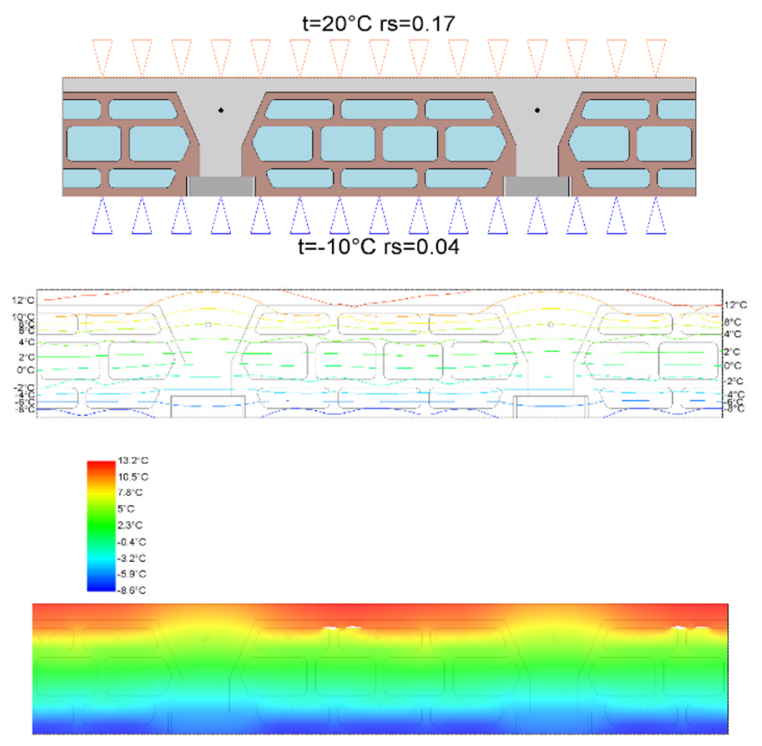

(a)
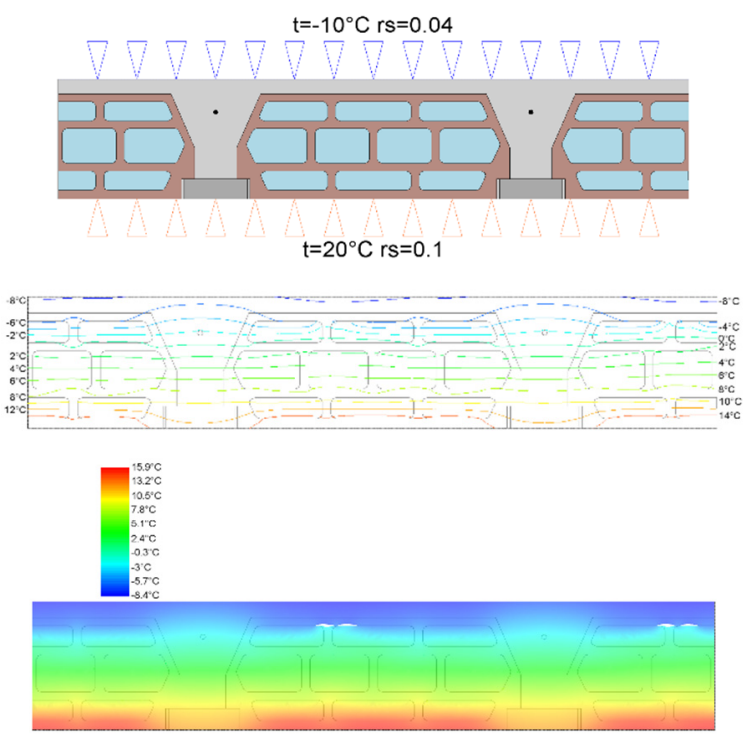

(b)

Figure 12. Results of Teriva Termo ceiling calculations: (a) flow upwards, (b) flow downwards.

Table 13. Values of thermal parameters of various Teriva Panel ceiling variants.

\begin{tabular}{ccccc}
\hline Parameter & Unit & Teriva Panel 160 & Teriva Panel 180 & Teriva Panel 200 \\
\hline$R_{T}$ flow upwards & $\left(\mathrm{m}^{2} \cdot \mathrm{K}\right) / \mathrm{W}$ & 0.199 & 0.220 & 0.241 \\
$R_{T}$ flow downwards & $\left(\mathrm{m}^{2} \cdot \mathrm{K}\right) / \mathrm{W}$ & 0.213 & 0.222 & 0.241 \\
$R_{U}$ flow upwards & $\left(\mathrm{m}^{2} \cdot \mathrm{K}\right) / \mathrm{W}$ & 0.339 & 0.360 & 0.381 \\
$R_{U}$ flow downwards & $\left(\mathrm{m}^{2} \cdot \mathrm{K}\right) / \mathrm{W}$ & 0.413 & 0.432 & 0.451 \\
U flow upwards & $\mathrm{W} /\left(\mathrm{m}^{2} \cdot \mathrm{K}\right)$ & 2.947 & 2.775 & 2.623 \\
$U$ flow downwards & $\mathrm{W} /\left(\mathrm{m}^{2} \cdot \mathrm{K}\right)$ & 2.420 & 2.317 & 2.219 \\
\hline
\end{tabular}


Table 14. Values of thermal parameters of Smart and Teriva ceilings: Base, Plus and Termo.

\begin{tabular}{cccccc}
\hline Parameter & Unit & Smart & Teriva Base & Teriva Plus & Teriva Termo \\
\hline$R_{T}$ flow upwards & $\left(\mathrm{m}^{2} \cdot \mathrm{K}\right) / \mathrm{W}$ & 0.119 & 0.263 & 0.326 & 0.326 \\
$R_{T}$ flow downwards & $\left(\mathrm{m}^{2} \cdot \mathrm{K}\right) / \mathrm{W}$ & 0.119 & 0.263 & 0.325 & 0.325 \\
$R_{U}$ flow upwards & $\left(\mathrm{m}^{2} \cdot \mathrm{K}\right) / \mathrm{W}$ & 0.259 & 0.403 & 0.466 & 0.561 \\
$R_{U}$ flow downwards & $\left(\mathrm{m}^{2} \cdot \mathrm{K}\right) / \mathrm{W}$ & 0.329 & 0.473 & 0.535 & 0.630 \\
U flow upwards & $\mathrm{W} /\left(\mathrm{m}^{2} \cdot \mathrm{K}\right)$ & 3.859 & 2.480 & 2.146 & 1.783 \\
$U$ flow downwards & $\mathrm{W} /\left(\mathrm{m}^{2} \cdot \mathrm{K}\right)$ & 3.038 & 2.114 & 1.868 & 1.588 \\
\hline
\end{tabular}

Comparing the results of numerical calculations with the calculations carried out in accordance with EN ISO 6946:2017 [28], it can be stated that the heat transfer coefficients obtained on the basis of numerical calculations are higher than those obtained on the basis of standard calculations. The smallest difference of almost $12 \%$ was obtained for the Teriva Panel ceiling with a height of $200 \mathrm{~mm}$. The biggest difference between the results of the calculations occurred in the case of the Smart ceiling, where the numerical simulations showed a $U$ factor $39 \%$ higher than in the calculations carried out in accordance with EN ISO 6946:2017 [28]. The percentage differences between the values of the heat transfer coefficient $U$, calculated in accordance with the standard and obtained from numerical analyses, are given in Table 15.

Table 15. Percentage differences between the results of calculations carried out in accordance with EN ISO 6946:2017 [28], and numerical calculations.

\begin{tabular}{cccccccc}
\hline Ceiling & $\begin{array}{c}\text { Teriva } \\
\text { Panel 160 }\end{array}$ & $\begin{array}{c}\text { Teriva } \\
\text { Panel 180 }\end{array}$ & $\begin{array}{c}\text { Teriva } \\
\text { Panel 200 }\end{array}$ & Smart & Teriva Base & Teriva Plus & Teriva Termo \\
\hline $\begin{array}{c}\text { Flow } \\
\text { upwards } \\
\text { Flow }\end{array}$ & 14.9 & 13.5 & 12.0 & 20.4 & 19.1 & 22.3 & 30.9 \\
downwards & 28.2 & 27.2 & 25.8 & 39.4 & 31.1 & 32.7 & 38.8 \\
\hline
\end{tabular}

Numerical calculations have always resulted in higher $U$ values. Greater differences in the results of standard and numerical calculations were observed at downward flow than at upward flow. This is due to different heat transfer resistance values used in traditional and numerical calculations.

When calculating the thermal characteristics of building partitions, the EN ISO 6946:2017 standard is most often used [28]. The heat exchange through ceilings takes place by conduction, convection and radiation. In the case of air-filled spaces in the ceiling, the mathematical description of free convection in free spaces consists in providing a system of equations that includes the equation of continuity, the momentum equation, and the energy conservation equation with boundary conditions. If the spaces have a regular shape, it is possible to replace the complicated description of the phenomenon by assuming that the heat transport in the cavity is one-dimensional heat conduction with a modified air conductivity coefficient. The intensity of air circulation as a result of convection depends on the geometries of the free space (its height and width) and the difference in temperature of the surrounding walls. This phenomenon can be characterized by an equivalent thermal conductivity coefficient, which was adopted for calculations on the basis of nomograms given in the paper [22].

For the numerical calculations of the airspace, the actual geometries of the voids were given. The thermal conductivity coefficient was selected from the program's material database. A different way of taking convection into account in the ceiling spaces that are filled with air indicated the expected possibility of obtaining various results of numerical simulations and normative calculations with the additional taking account of the equivalent air heat conductivity coefficient. In the case of Teriva Panel ceilings, where there are no air voids, the differences at upward flow of $12 \%-14.9 \%$ are not too great. With a downward flow, the differences are $25.8 \%-28.2 \%$. For cases of ceilings with air hollow blocks, the results obtained from the numerical calculations differ significantly from the results. With an 
upward flow, the differences are $19.1 \%-30.9 \%$, and $31.1 \%-39.4 \%$ with a downward flow. As mentioned above, these differences result from the geometries of the airspace in which convective heat exchange occurs, and from how convection phenomena are taken into account in the calculations.

\section{Conclusions}

The calculations carried out showed that the finite element method (FEM) can be used to determine the heat transfer coefficient of reinforced concrete ceilings. The differences between the calculations carried out in accordance with EN ISO 6946:2017 [28] are 12\%-39\%. It should be emphasized that in traditional calculations it is necessary to use simplifications, which especially in the case of complex geometries of ceiling cross-sections, affects the results of calculations. The way of taking into account air voids in both calculation methods has the greatest impact on the calculation results. In the traditional method, an equivalent thermal conductivity coefficient was used, while in the numerical analysis, the coefficient was selected from the program's material database based on the geometries of the voids. Therefore, it should be concluded that numerical methods give more accurate results.

Author Contributions: Conceptualization, Ł.D., R.W. and A.K.; methodology, R.W.; software, Ł.D.; validation, Ł.D. and R.W.; formal analysis, Ł.D. and R.W.; writing-original draft preparation, Ł.D., R.W. and A.K.; writing一review and editing, Ł.D., R.W. and A.K.; visualization, Ł.D.; supervision, A.K.; funding acquisition, A.K. All authors have read and agreed to the published version of the manuscript.

Funding: This research received no external funding.

Conflicts of Interest: The authors declare no conflict of interest.

\section{References}

1. Lucero-Álvarez, J.; Rodríguez-Muñoz, N.A.; Martín-Domínguez, I.R. The effects of roof and wall insulation on the energy costs of low income housing in Mexico. Sustainability 2016, 8, 590. [CrossRef]

2. Dixit, A.K.; Roul, M.K.; Panda, B.C. Thermal performance of insulated roof slabs. Recent Adv. Sustain. Concr. Technol. 2018, 12, 165-170.

3. Wang, H.; Chiang, P.C.; Cai, Y.; Li, C.; Wang, X.; Chen, T.L.; Wei, S.; Huang, Q. Application of wall and insulation materials on green building: A review. Sustainability 2018, 10, 3331. [CrossRef]

4. Schabowicz, K. Non-destructive testing of materials in civil engineering. Materials 2019, 12, 3237. [CrossRef] [PubMed]

5. Nowak, R.; Orłowicz, R.; Rutkowski, R. Use of TLS (LiDAR) for building diagnostics with the example of a historic building in Karlino. Buildings 2020, 10, 24. [CrossRef]

6. Grebowski, K.; Rucka, M.; Wilde, K. Non-destructive testing of a sport tribune under synchronized crowd-induced excitation using vibration analysis. Materials 2019, 12, 2148. [CrossRef]

7. Jasiński, R.; Drobiec, Ł.; Mazur, W. Validation of selected non-destructive methods for determining the compressive strength of masonry units made of autoclaved aerated concrete. Materials 2019, 12, 389. [CrossRef]

8. Hoła, J.; Schabowicz, K. New technique of nondestructive assessment of concrete strength using artificial intelligence. NDT E Int. 2005, 38, 251-259. [CrossRef]

9. Schabowicz, K.; Hoła, B. Application of artificial neural networks in predicting earthmoving machinery effectiveness ratios. Arch. Civ. Mech. Eng. 2008, 8, 73-84. [CrossRef]

10. Ziolkowski, P.; Demczynski, S.; Niedostatkiewicz, M. Assessment of failure occurrence rate for concrete machine foundations used in gas and oil industry by machine learning. Appl. Sci. 2019, 9, 3267. [CrossRef]

11. Ziolkowski, P.; Niedostatkiewicz, M. Machine learning techniques in concrete mix design. Materials 2019, 12, 1256. [CrossRef] [PubMed]

12. Giannakis, I.; Giannopoulos, A.; Warren, C. A machine learning scheme for estimating the diameter of reinforcing bars using ground penetrating radar. IEEE Geosci. Remote Sens. Lett. 2020, 99, 1-5. [CrossRef]

13. Drobiec, Ł.; Jasiński, R.; Mazur, W. Accuracy of eddy-current and radar methods used in reinforcement detection. Materials 2019, 12, 1168. [CrossRef] [PubMed] 
14. Schabowicz, K. Ultrasonic tomography-The latest nondestructive technique for testing concrete members-Description, test methodology, application example. Arch. Civ. Mech. Eng. 2014, 14, $295-303$. [CrossRef]

15. Antczak, E.; Defer, D.; Elaoami, M.; Chauchois, A.; Duthoit, B. Monitoring and thermal characterisation of cement matrix materials using non-destructive testing. NDT E Int. 2007, 40, 428-438. [CrossRef]

16. Balageas, D.; Maldague, X.; Burleigh, D.; Vavilov, V.P.; Oswald-Tranta, B.; Roche, J.M.; Pradere, C.; Carlomagno, G.M. Thermal (IR) and other NDT techniques for improved material inspection. J. Nondestruct. Eval. 2016, 35, 1-17. [CrossRef]

17. Wyczółkowski, R.; Musiał, D. Experimental tests for the occurence of convective heat transfer within the bed of rectangular steel profiles. Arch. Thermodyn. 2012, 33, 89-100. [CrossRef]

18. Wyczółkowski, R.; Benduch, A. The experimental study of the effective thermal conductivity of bundles of rectangular steel sections. Civ. Environ. Eng. Rep. 2014, 14, 119-132. [CrossRef]

19. Bai, G.; Du, N.; Xu, Y.; Qin, C. Study on the thermal properties of hollow shale blocks as self-insulating wall materials. Adv. Mater. Sci. Eng. 2017, 2017, 9432145. [CrossRef]

20. Ma, S.; Bao, P.; Jiang, N. Experimental study of gypsum-concrete dense-column composite boards with external thermal insulation systems. Appl. Sci. 2020, 10, 1976. [CrossRef]

21. Steidl, T.; Krause, P. Moisture transport in cellular concrete walls with the connector for thermal insulation. Period. Polytech. Civ. Eng. 2018, 62, 986-991.

22. Wyczółkowski, R.; Kisiołek, A. Analysis of thermal insulation properties of the Konbet Termo ceiling system. Mat. Bud. 2011, 461, 41-42. (In Polish)

23. Urbán, D.; Roozen, N.B.; Muellner, H.; Zat’ko, P.; Niemczanowski, A.; Rychtáriková, M.; Glorieux, C. Vibrometry assessment of the external thermal composite insulation systems influence on the façade airborne sound insulation. Appl. Sci. 2018, 8, 703. [CrossRef]

24. Nowoświat, A.; Skrzypczyk, J.; Krause, P.; Steidl, T.; Winkler-Skalana, A. Estimation of thermal transmittance based on temperature measurements with the application of perturbation numbers. Heat Mass Transf. 2018, 54, 1477-1489.

25. Babota, F.; Moga, L. Computation and analysis of corrected thermal insulation in a common dwelling building in Romania, in various thermal insulation variants-The slab over the soil. Procedia Manuf. 2018, 22, 352-357. [CrossRef]

26. Ciurej, H.; Piekarczyk, M. Experimental research and integrated FEM modelling for sheet roof covering with thermal insulation. Mech. Mech. Eng. 2010, 14, 183-192.

27. Ascione, F.; Bianco, N.; De Stasio, C.; Mauro, G.M.; Vanoli, G.P. Thermal dynamic insulation: Numerical modeling in a transient regime and application to alternative aviary houses. Energy Procedia 2015, 75, 1711-1721. [CrossRef]

28. ISO. ISO 6946:2017 Building Components and Building Elements. Thermal Resistance and Thermal Transmittance. Calculation Methods; ISO: Geneva, Switzerland, 2017.

(C) 2020 by the authors. Licensee MDPI, Basel, Switzerland. This article is an open access article distributed under the terms and conditions of the Creative Commons Attribution (CC BY) license (http://creativecommons.org/licenses/by/4.0/). 